\title{
THE INFLUENCE OF SHARED MENTAL MODELS BETWEEN THE CIO AND THE TOP MANAGEMENT TEAM ON THE STRATEGIC ALIGNMENT OF INFORMATION SYSTEMS: A COMPARISON BETWEEN BRAZILIAN AND US COMPANIES
}

\author{
Nicolau Reinhard \\ José Ricardo Bigueti \\ University of São Paulo, São Paulo, São Paulo, Brazil
}

\begin{abstract}
The gap in the understanding between the chief information officer (CIO) and the management team (TMT) has been cited as a contributing factor to their often troubled relationship. The objective of this study is to examine the development of shared mental models (SMMs) between the CIO and TMT about the role of information systems in the organization. An SMM is conceptualized as a multidimensional construct spanning the dimensions of shared language and shared understanding. The study posits that knowledge exchange mechanisms and relational similarity between the CIO and TMT are key antecedents to the development of SMMs. SMMs between the CIO and TMT are expected to guide the strategic orientation of the organization and may influence strategic alignment and organizational outcomes. The model was tested via a field survey of CIO - TMT pairs using structural equation modeling. Results show that relational similarity and formal mechanisms of knowledge exchange (e.g., formal CIO membership in the TMT, CIO hierarchical level, and formal educational mechanisms by the CIO) are important to the development of SMMs. Contrary to expectations, informal social mechanisms of knowledge exchange and physical proximity were not significantly related to SMMs.
\end{abstract}

Keywords: IS alignment, CIO, shared mental models, knowledge exchange, Brazilian companies

\footnotetext{
Manuscript first received/Recebido em 17/09/2011 Manuscript accepted/Aprovado em: 08/07/2013

Address for correspondence / Endereço para correspondência

Nicolau Reinhard, Nicolau Reinhard is a professor of management at the School of Economics, Administration and Accounting of the University of São Paulo, Brasil. His research interests and publications are related to Management of the IT function, the use of IT in Public Administration and Information Systems Implementation. Prof. Reinhard has a degree in Engineering, a $\mathrm{PhD}$ in Management, and, besides his academic career, has held executive and consulting positions in IT management in private and public organizations. School of Economics, Administration and Accounting University of São Paulo Av. Prof. Luciano Gualberto, 908 05508-010 São Paulo - Brasil Tel: (55) 113091-5838 E-mail: reinhard@usp.br
}

José Ricardo Bigueti, has a bachelor degree in Computer Science, an MBA in Information Technology Management and an MSc in Administration from the University of São Paulo. He is presently a Senior I/S Security Manager for The Dow Chemical Co., in Midland, Michigan, USA. School of Economics, Administration and Accounting, University of São Paulo Av. Prof. Luciano Gualberto, 908 05508-010 São Paulo - Brasil Tel: (55) 11-3091-5838 E-mail: rbigueti@ hotmail.com 


\section{INTRODUCTION}

Strategic IS alignment has been reported as one of the major preoccupations of the Chief Information Officer (CIO) (Reich; Benbasat, 2000; Chan, 2002; Leonard; Seddon, 2012), IS alignment being defined as the congruence between the business strategy, managed by the Top Management Team (TMT), and the IS strategy in the organization (Henderson; Venkatraman, 1999; Sabherwal, 2001).

Despite their heavy investments in IS, many organizations have not been able to reap significant business results. In fact, IS investments will not improve business performance unless they are made according to an IS strategy that is aligned with the organization's business strategy. This alignment has proved to be a hard to achieve goal (Weill, 1990).

Understanding the organizational factors that contribute to this goal has been a research objective for a long time (Chan, 2002; Ball et al, 2003), with communication between the CIO and the TMT, organizational characteristics and an understanding of the IS competencies (Reich; Benbasat, 2000; Chan, 2002) among them.

This paper focuses on the shared language and shared understanding between the CIO and the TMT that, collectively, constitute the Shared Mental Model (SMM), on the strategic IS alignment and the factors leading to the development of this shared language and understanding. CIOs are expected to be key contributors in this process and, therefore, this paper will focus on the CIOs and on their the importance achieving the sharing of language and understanding with the TMT. (Preston; Karahana, 2009; Preston, 2004).

The research questions are

1 What is the relationship between the SMM and the strategic IS alignment?

2. What are the antecedents to a SMM of the CIO and the TMT?

3. Is there a difference between Brazilian and US companies in this respect?

As a by-product, the study also aims at validating in a different context (the IT function in Brazilian business), the research model and instruments developed by Preston 2004, including the questionnaire and constructs for SMM.

This paper also aims at verifying the applicability of SMM concepts and management principles developed in different cultural and business contexts in Brazilian companies.

\section{LITERATURE REVIEW AND RESEARCH MODEL CONSTRUCTS}

Our research is based on a basic conceptual model, developed by Preston 2004. The components of this conceptual model are depicted in Figure 1. 


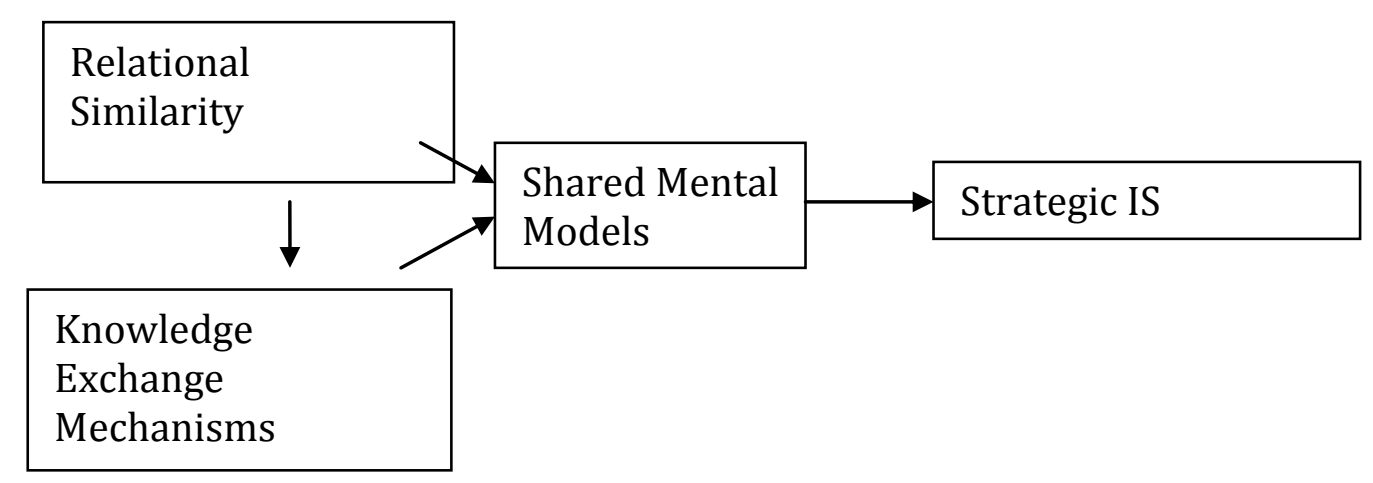

\section{Figure 1 The basic conceptual model}

Previous research has indicated Mechanisms for knowledge exchange and Relational similarity as antecedents to SMM. Knowledge exchange mechanisms comprise knowledge systems and mechanisms for educating the CIO and the TMT. This includes structure (for example, the CIO's position in the hierarchy and his/her participation in the TMT), physical systems (the CIO's office being located close to the TMT office) and social systems (such as, informal interaction between the CIO and the TMT), thus allowing the CIO to be proactive in facilitating the knowledge exchange by educating the TMT and therefore contributing to the development of a SMM. (PRESTON, 2004)

Relational similarity considers the demographic similarity and the similarity of past experiences of the CIO and the TMT. The Upper Echelon Theory is used to link these factors to the organization's strategies (for example, the IS alignment). (Hambrick; Mason, 1984). The principle of attraction by similarity provides a basis for linking relational similarity with knowledge exchange mechanisms, especially social knowledge systems. (Orpen, 1984; Byrne, 1971).

\subsection{Strategic IS alignment}

Strategic alignment is consistently ranked as a key issue for IS managers, due to its strategic benefits to the organization. This has led to a strong tradition in IS alignment research, with different developments in theory, addressing the changing issues faced by IS managers. (Leonard; Seddon, 2012)

For this research IS alignment is defined as the congruence between the business and IS strategy in the organization: the degree in which the mission, goals and plans for IT support and are supported by the mission, goals and plans for the business (Reich; Benbasat, 1996). Past research has indicated two benefits of this strategic alignment: IS effectiveness (Chan, 2002) and IS higher performance (Sabherwal; Chan, 2000; Sabherwal et al, 2001).

Strategic IS alignment, as opposed to structural IS alignment, focuses on the intellectual dimension (the content of the organization's plans) and social dimension (the actors in the organization, their values, communication and understanding of their domains). The intellectual dimension is a state or a result (with antecedents being the alignment, the communication among the actors, the business and IS plans), while the social dimension is the congruent understanding of the persons involved in the alignment (Reich; Benbasat, 2000). 
Other antecedents for the strategic alignment of IS in the organization are: the Relationship between the CIO and the TMT (Rockart et al, 1996; Chan, 2002), shared knowledge and understanding between the CIO and the TMT (Armstrong; Sambamurthy, 1999; Reich; Benbasat, 2000), the organization's business strategy (Reich; Benbasat, 2000; Sabherwal), senior executives' planning process (Reich; Benbasat, 2000; Chan, 2000). Strategic IS alignment has also been shown to be linked to agility and firm performance (Tallon; Pinsonneault, 2011)

\subsection{Mental Models and Shared Mental Models}

There are multiple definitions of Mental Models (MM), such as set of beliefs, understandings, mental representations, cognitive constructs, cognitive systems, assumptions, habits and paradigms (Denzau; North, 1994), (Van den Bosch; Volberda, 1999), (Peterson et al, 2000).

The Shared Mental Model (SMM) has also multiple definitions in the literature. Examples are: values, myths, shared standard operational procedures and beliefs (KIM, 1993); an understanding of the organization or mental representation of the group's key elements, a frame of the structure, processes and tasks of a group, which its members have in common (Mohammed et al, 2000). In this paper, we will use Preston's (Preston 2004, p.18) definition: "Shared Mental Models are shared beliefs and understanding of the role of Information Systems in the organization, together with a common shared language that has its own vocabulary and nuances". This definition suggests two different dimensions in SMM: a shared language and a shared understanding.

According to Preston (2004), the strategic alignment of IS can be achieved through this multidimensional SMM between the CIO and the TMT. Previous research, although not using the same language, also supports this contention. (Madhavan; Grover, 1998) (Lederer; Mendelow, 1987)

The shared language dimension of SMM between the CIO and the TMT has clear implications for the CIO. His/her success will depend on how well this executive communicates with the other executives in the organization. Nelson and Cooprider (1996) argue that a shared language can create a positive social influence among the top managers; therefore the $\mathrm{CIO}$ should communicate using business terms comprehensible to the top manager, instead of a technical language full of acronyms (Feeney et al, 1992).

\subsubsection{Shared understanding}

SMM have been associated with shared understanding (Mohammed et al, 2000; Peterson et al, 2000), congruence of visions (Feeny et al, 1992; Kim, 1993). Other researchers have associated SMM with knowledge shared among individuals or groups: shared knowledge structures (Richards, 2001); shared social knowledge structures (Swaab et al, 2002); and shared previous knowledge (Madhavan; Groover, 1998).

Shared understanding is not the same as shared knowledge. In fact, shared understanding is facilitated by the mechanisms of knowledge exchange. Shared understanding can be obtained when the CIO and the TMT have respectively high levels of business knowledge and IS knowledge and exchange this knowledge (Armstrong; Sambamurthy, 1999). These exchange mechanisms will allow the CIO and the TMT understand how IS can be best used to improve the organization's performance.

Studies that have focused on the SMM antecedents have identified communication and feedback (Rasker; Post, 2000) and negotiation (Swaab, 2002) as 
key elements for the development of SMM among the parties. Preston (Preston, 2004) extends this list to include the following antecedents of SMM:knowledge exchange mechanisms and relational similarity.

There is evidence that the CIO and the TMT often do not have a shared language and understanding of the role of IS, due to a limited IS strategy of the TMT and a limited business knowledge of the CIO (Armstrong; Sambamurthy, 1999). Knowledge exchange mechanisms are therefore an important antecedent for the alignment of the IS strategy.

The literature presents two primary mechanisms for knowledge exchange that contribute to the development of a SMM between the CIO and the TMT: knowledge systems and the CIO's education mechanisms.

\subsubsection{Knowledge systems}

Organizations provide their members with multiple ways to interact and exchange knowledge. According to Nahapiet and Ghoshal (1998) organizational competencies to generate and share knowledge derive from factors, such as special means to create and transfer tacit knowledge; the organizational principles according to which individual and functional abilities are structured, coordinated and communicated and used by individuals to cooperate; the nature of organizations as social communities. For individuals to transfer knowledge, they have to have the ability to interact with one another. Systems in the organization that provide this ability are called knowledge systems.

According to Armstrong and Sambamurthy (1999) formal and informal interactions between top management allows stronger knowledge integration. Knowledge systems reflect the possibilities of CIO and TMT to access richer channels, develop more effective social relations and communication patterns (Armstrong; Sambamurthy, 1999)

Three dimensions can be identified in a knowledge system:

1 structural knowledge systems, comprising the formal interactions permitted by the established organizational structure,

2 physical knowledge systems, related to the interactions allowed by the proximity of the CIO and TMT's offices and

3 Social knowledge systems, related to the informal interactions among CIO and TMT.

\section{Structural Knowledge Systems}

Structural knowledge systems allow the CIO to interact with the TMT. In addition to the formal communication channels, these systems include the CIO's hierarchical level (Feeny et al, 1992; Watson, 1990) and his/her participation in the TMT itself (Watson, 1990).

The higher the CIO's hierarchical position, the higher his/her opportunity to understand the corporation and its strategy (Lederer; Mendelow, 1987), impact organizational decisions (Schrage, 1996), exercise power (Karimi; Gupta 1996; Rockart et al, 1996; Smaltz, 1999) and ultimately corporate effectiveness (Armstrong, 1995). 
Participation in the TMT has been shown to be vital for the CIO's effectiveness (Rockart et al, 1996, Smaltz, 1999), allowing an effective information exchange information with the TMT. In fact, if the TMT does not fully accept the CIO and allow his/her participation, this will minimize his/her influence in the organization (Smaltz, 1999).

\section{Physical Knowledge Systems}

Organizational proximity is defined as persons occupying the same space, with the opportunity and psychological obligation to face-to-face communication (Monge et $a l, 1985)$. With an office located close to the TMT's, the CIO will increase his/her opportunity to engage in this face-to-face communication, allowing a more effective communication of complex messages and reaching a common perspective on ambiguous issues (Daft et al, 1987; Watson, 1990).

\section{Social Knowledge Systems}

Social knowledge systems focus on informal interactions contribute to communication and knowledge sharing (Alavi; Leidner, 2001), increase exchange of ideas and common understanding (Watson, 1990; Armstrong, 1995; Chan, 2002).

\subsubsection{CIO education mechanisms}

The literature indentifies the advantages of the CIO being allowed to formally educate the TMT about the IS competencies, in order to facilitate the common understanding between the CIO and the TMT. (Smaltz, 1999; Enns et al, 2003). Preston (2004) also indicates the importance of knowledge exchange facilitated by the CIO in educational activities.

As mentioned before, poor IS alignment is also caused due to the lack of the TMT's understanding of IS strategic competencies. The CIO's educational function can help bridging this gap. This knowledge exchange is not necessarily captured by the organization's knowledge system. The CIO can use every opportunity for interaction with the TMT, but also formal events to educate the TMT about IS competencies. According to Preston (2004) these mechanisms contribute to the development of sharing Mental Models between the CIO and the TMT.

\subsubsection{Relational Similarity}

Relational Similarity is defined as similarity between the CIO and the TMT in basic characteristics, such as demographic (age and gender), past experiences (knowledge of the organization, time in executive position in the organization, functional origin, educational level and personal interests)

Upper Echelon Theory provides support for relating the basic characteristics of the TMT and the strategic IS alignment and between SMM and IS strategic alignment. This theory states that organizational results can be predicted from the basic characteristics of top level executives (not just the CEO, but of the dominating coalition), such as gender, age, past experiences, education, etc and that these results reflect their values and perceptions (Hambrick; Mason, 1984). These results include performance and strategic decisions.

Hambrick and Mason (1984) have argued that basic characteristics reflect one's person cognitive map and therefore impact their capacity to interpret data and transform them into knowledge. Thus making strategic business and IS decisions should be 
influenced by the managers' basic characteristics: demographic and those related to past experiences.

Preston (2004), based on the Upper Echelon Theory, proposes SMM as a mediating variable to capture the cognitive map of the dominating coalition that can then be used to mediate the relationship of past experiences and demographic characteristics of the CIO and TMT and the organization's strategic choices, leading to the IS alignment.

\section{Demographic Similarity}

Demographic Similarity refers to comparable demographic characteristics of members of couples or groups that are in a position of involvement in regular interaction. The conceptual basis for relational demography is the paradigm of attraction by similiarity, which suggests that individuals tend to be attracted to those that are more similar to them.

Interpersonal attraction is based on the similarity of individuals on various dimensions, such as attitudes, age, gender, time in the organization, educational level, area of graduation, market experience, time in the team or company, functional or professional specialty (Allinson et al, 2001; Van der Vegt, 2002).

\section{THE RESEARCH MODEL}

The reference model and research method used in this research are based on Preston (2004), with adaptations to the Brazilian situation made by Bigueti in his MS dissertation (Bigueti, 2007). In this survey the term CIO is used in a rather loose form, referring to persons with different titles, as long as they are the principal or most influential IS/IT executives in the organization. (Grover et al, 1993; Armstrong, 1995).

TMT is defined as the CEO and the most senior and influential executives in the organization, reporting directly to the CEO. (Finkelstein; Hambrick, 1996).

Based on the previously discussed importance of the relationship between the CIO and the TMT, our research focuses on the couple CIO - TMT in the organization, positing the relationships depicted in Figure 2. 


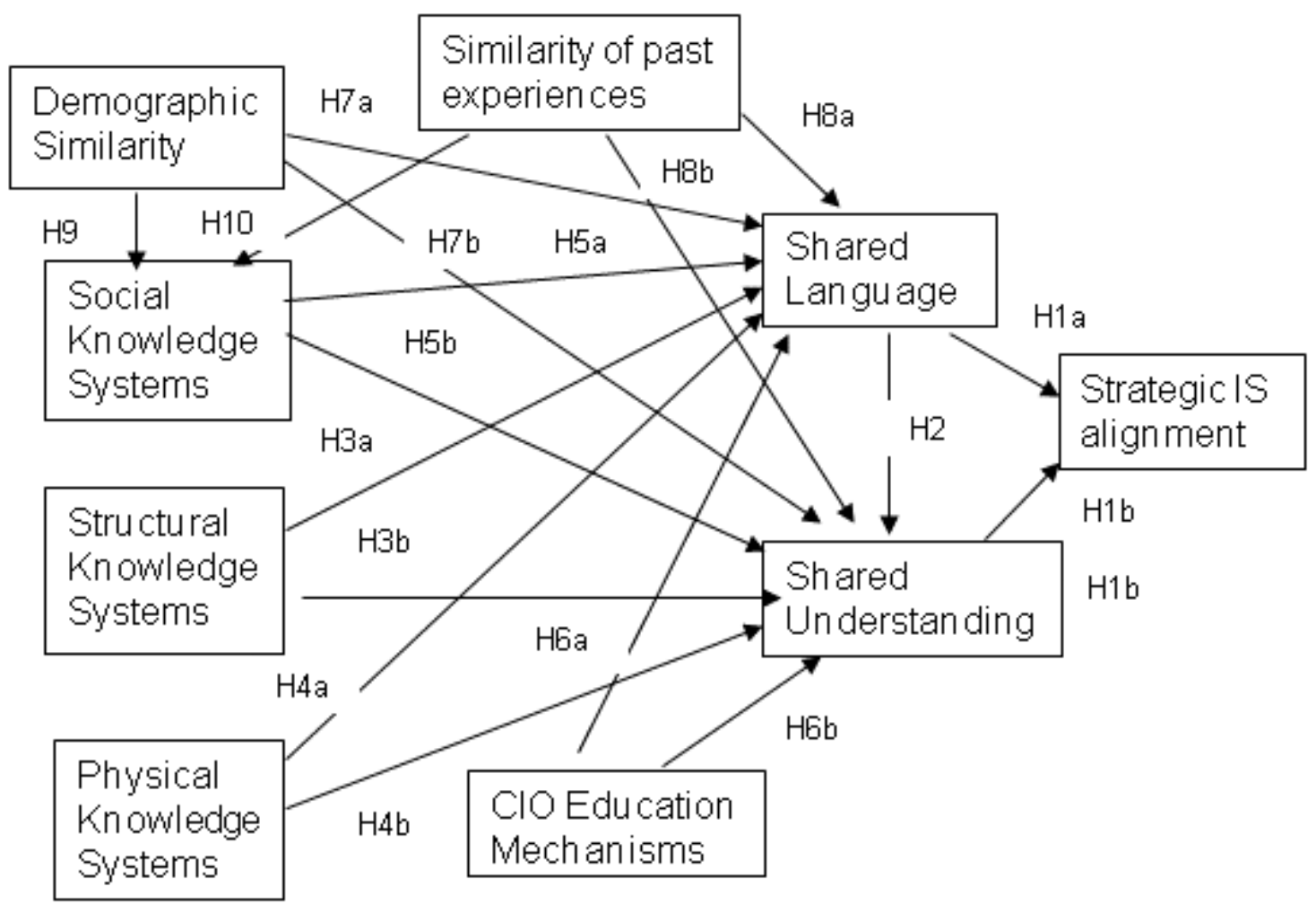

Figure 2 - Research model - constructs and hypothesized influence relationships

\subsection{Research hypotheses and Operationalization of Constructs}

There are two groups of hypotheses:

1. Related to the strategic IS alignment in the organization and

2. Related to the SMM between the CIO and the TMT.

\subsubsection{SMM and Strategic IS Alignment}

The literature provides evidence of the relationship between IS alignment and communication and common understanding between the CIO and the TMT. SMM should then contribute to provide a congruence of visions related to key IS issues and improve the alignment of business and IS decisions, providing the rationale for the following research hypotheses:

H1: high levels of SMM between the CIO and the TMT contribute to the alignment between IS and business strategies in the organization

H1a: high levels of shared language between the CIO and the TMT contribute to the alignment between IS and business strategies in the organization

H1b: high levels of shared understanding between the CIO and the TMT contribute to the alignment between IS and business strategies in the organization 


\subsubsection{Shared Language and Shared Understanding}

Nahapiet and Ghoshal (1998) and Boynton et al (1992, p.32) have shown that the creation of a shared understanding is unlikely in the absence of a common shared language [between the $\mathrm{CIO}$ and the TMT], therefore justifying the hypothesis:

$\mathrm{H} 2$ : a shared language between the CIO and the TMT contributes to a shared understanding between the CIO and the TMT on the role of IS in the organization

\subsubsection{Shared Mental Model antecedents}

Our research model considers three primary antecedents that contribute to the development of a SMM between the CIO and the TMT: knowledge systems (structural, physical and social), CIO education systems and relational similarity. All three are seen as influencing directly the SMM, while the relational similarity is also supposed to influence the organization's social knowledge system.

\subsubsection{Knowledge Systems and SMM}

Knowledge exchange, which is considered critical for the development of a SMM between the CIO and the TMT, can be achieved through structural knowledge systems, physical knowledge systems, social knowledge systems, according to authors (Armstrong; Sambmurthy, 1999). Two aspects of the structural knowledge systems are considered in the model, which, according to Feeny et AL (1992), are essential for the CIO's performance: direct reporting to the CIO and participation in the TMT. There is research indicating that these situations contribute to the development of SMM between the CIO and the TMT (Watson, 1990; Smaltz, 1999).

H3a: Structural knowledge systems contribute to the development of a shared language between the CIO and the TMT

H3b: Structural knowledge systems contribute to the development of shared understanding between the CIO and the TMT.

\subsubsection{Physical Knowledge Systems and SMM}

Physical proximity of the CIO and the TMT's offices influences communication and knowledge exchange, allowing the $\mathrm{CIO}$ a better perception of organizational objectives, of commonalities with the TMT and a more effective engagement in the management process. Therefore:

H4a: Physical knowledge systems contribute to the development a shared language between the CIO and the TMT.

H4b: Physical knowledge systems contribute to the development of a shared understanding between the CIO and the TMT on the role of IS in the organization.

\subsubsection{Social Knowledge Systems and SMM}

Frequent informal networking helps developing SMM among individuals, by developing shared language and understanding (Denzau; North, 1994). Successful CIOs value informal communication and socialize with the TMT, becoming able to evaluate their motivations, meanings and priorities and testing their business vision (Earl; Feeny, 1994). Therefore: 
H5a: Social knowledge systems contribute to the development of a shared language between the CIO and the TMT.

H5b: Social knowledge systems contribute to the development of a shared understanding between the CIO and the TMT on the role of IS in the organization.

\subsubsection{CIO education mechanisms and SMM}

CIOs should use their specialized IS knowledge to continually educate the TMT on IS competencies and help them interpreting new external ideas, experiences and success stories and manage expectations and thus maintaining their SMMs. (Lederer; Mendelow, 1987). Therefore:

H6a: The CIO's educational mechanisms contribute to the development of a shared language between the CIO and the TMT.

H6b: The CIO's educational mechanisms contribute to the development of a shared understanding between the CIO and the TMT on the role of IS in the organization.

\subsubsection{Relational Similarity and SMM}

Individuals with a similarity of demographic characteristics and past experiences tend to develop common language, attitudes, perceptions, understanding, values and beliefs and a convergent mental model (Denzau; North, 1994; Hodgkinson; JOHNSON, 1994). Therefore:

H7a: Demographic similarity contributes to the development of a shared language between the CIO and the TMT.

H7b: Demographic similarity contributes to the development of a shared understanding between the CIO and the TMT on the role of IS in the organization.

H8a: similarity of past experiences contributes to the development of a shared language between the CIO and the TMT.

H8b: similarity of past experiences contributes to the development of a shared understanding between the CIO and the TMT on the role of IS in the organization.

\subsubsection{Relational Similarity and Social Knowledge Systems}

Relational similarity should also contribute to the informal interaction among individuals.

Relational similarity of the CIO and the TMT should benefit their interaction, since individuals with similar demographics and past experiences tend to communicate, act favorably and value their association more than dissimilar groups. Therefore:

H9: Demographic similarity between the CIO and the TMT contributes to the development of social knowledge systems (i.e. the increase of informal interaction between the $\mathrm{CIO}$ and the TMT)

H10: similarity of past experiences between the CIO and the TMT contributes to the development of social knowledge systems (i.e. the increase of informal interaction between the CIO and the TMT)

\subsection{Operationalization of the constructs}

The operationalization of the constructs and survey questionnaire was adapted from Preston (2004) with the translation of the survey questions. The questionnaire was 
validated by a sample of local CIOs and TMT in order to assure the adequate understanding of the questions.

\section{RESEARCH METHODOLOGY}

This survey is based on a convenience sample of large Brazilian companies, using a structured questionnaire to be answered by pairs of CIOs and TMT members of the same company.

\subsection{Operationalization and measurement of the variables}

Demographic Similarity and Similarity of Past Experiences: This construct includes the questions about age, gender, education background, time in the organization and the present position and experience in other functions. These dimensions, measured for the CIO and the TMT, are the input to a similarity measure, obtained from an adapted Euclidian distance function between the CIO and the TMT (Wagner et al, 1984; Young; Buchholtz, 2002). The operationalization of the variables, presented in Figure 2, follows the Preston 2004 study, in order to allow the comparison of results of the US and Brazilian cases.

\subsection{Target Population and Survey Sample}

Since the research focuses on the development of SMM between the CIO and the TMT, only organizations that have an IS manager in executive position are considered in the sample.

The requirement that the survey be responded by pairs of CIOs and CEOs (or TMT members), required special motivation of otherwise overloaded individuals, for which the influence provided by national industry and professional associations, as well as the researcher's networks was instrumental in obtaining the survey sample and the needed follow-up mechanisms.

The questionnaire was first distributed over the Internet (by e-mail addressed to potential respondents with a link to the questionnaire web page), thus also ensuring the respondents' anonymity, with the already mentioned follow-up, resulting in respondents from multiple segments: private companies of varied sizes, in the industry and service segments, with national and multinational capital.

\subsection{Data collection}

The survey consisted of two questionnaires, one for the CIO and the other for the TMT member. For a questionnaire to be considered valid it had to be responded in pairs for each company.

Several organizations provided contacts and encouraged their member to answer: GUI, a group of 16 CIOs of large companies, GETI, another association of IT executives of various industries, ABIQUIM, the Brazilian Association of Chemical Industries, AMCHAM, the American-Brazilian Chamber of Commerce, USP-MBA alumni, the association of MBA alumni of the University of São Paulo. The data were collected between January and April 2007. 
The e-mail referring to the questionnaires, with letters of recommendation from the Associations Leadership, was sent initially to the companies' CIOs, asking them to provide a respondent from their TMT.

\section{RESULTS ANALYSIS}

\subsection{Descriptive statistics}

Response rates for surveys requiring CIO CEO paired responses are usually low, with reported 7 to $20 \%$ response rates. In our research 180 companies were contacted, resulting in 62 reponses, with 35 usable response pairs, a 32.2\% valid response rate.

The breakdown of responses by control variable is presented in Table 5

One of our basic goals was to identify differences of SMM development and IS alignment between Brazilian companies and multinational companies (the other being the comparison with the US-based Preston 2004 study).

However, an ANOVA variance analysis on the national/multinational variable and also the service/industry classification showed no significant difference among the groups. Therefore the hypotheses were tested for the responses as a single group.

The data collection process led to a sample that contains large companies only, with a breakdown by segment and capital origin presented in Table 1

\begin{tabular}{|l|c|c|}
\hline Segment & National & Multinational \\
\hline Services & 4 & 6 \\
\hline Industry & & \\
\hline Chemical-Petrochemical & 3 & 10 \\
\hline Cosmetics & 2 & 1 \\
\hline Food & 1 & 0 \\
\hline Mechanical & 1 & 3 \\
\hline $\begin{array}{l}\text { Consumer } \\
\text { goods/electronics }\end{array}$ & 1 & 3 \\
\hline Total & 12 & 23 \\
\hline
\end{tabular}

Table 1: Distribution of responses by industry and capital ownership

\subsection{Factor Analysis and Hypotheses testing}

Construct validation: The structuring of the constructs from the basic variables (questionnaire items) was validated through a confirmatory Factor Analysis, demonstrating the validity of all constructs in terms of factor loads, internal consistency and discriminant validity. 


\subsubsection{Hypotheses Testing}

In order to maintain the compatibility with the Preston 2004 study, the test of hypotheses will be made using PLS Partial Least Squares, a technique sufficiently robust for small samples.

Table 2 presents the results of the Hypotheses test and the comparison with the results of the Preston 2004 study, highlighting the differences in findings.

\begin{tabular}{|c|c|c|}
\hline Hypotheses & Brazil & PRESTON \\
\hline H1a: Shared language $\rightarrow$ Strategic IS alignment & NS & NS \\
\hline H1b: Shared understanding $\rightarrow$ Strategic IS alignment & $\mathrm{S}(*)$ & $\mathrm{S}(* *)$ \\
\hline H2: Shared language $\rightarrow$ Shared understanding & $\mathrm{S}(*)$ & $\mathrm{S}(* *)$ \\
\hline H3a: Structural knowledge system $\rightarrow$ Shared language & NS & NS \\
\hline H3b: Structural knowledge system $\rightarrow$ Shared understanding & $\mathrm{S}(*)$ & $\mathrm{S}(* *)$ \\
\hline H4a: Physical knowledge system $\rightarrow$ Shared language & NS & $\mathrm{S}(* *)$ \\
\hline H4b: Physical knowledge system $\rightarrow$ Shared understanding & NS & NS \\
\hline H5a: Social knowledge system $\rightarrow$ Shared language & NS & NS \\
\hline H5b: Social knowledge system $\rightarrow$ Shared understanding & NS & NS \\
\hline H6a: CIO education mechanisms $\rightarrow$ Shared language & NS & NS \\
\hline H6b: CIO education mechanisms $\rightarrow$ Shared understanding & $\mathrm{S}(*)$ & $\mathrm{S}(* *)$ \\
\hline H7a: Demographic similarity $\rightarrow$ Shared language & NS & $\mathrm{NSt}$ \\
\hline H7b: Demographic similarity $\rightarrow$ Shared understanding & NS & NS \\
\hline H8a: Past experiences similarity $\rightarrow$ Shared language & NS & $\mathrm{S}(* *)$ \\
\hline H8b: Past experiences similarity $\rightarrow$ Shared understanding & NS & NS \\
\hline H9: Demographic similarity $\rightarrow$ Social knowledge system & $\mathrm{S}(*)$ & $\mathrm{S}(* *)$ \\
\hline H10: Past experiences similarity $\rightarrow$ Social knowledge system & $\mathrm{S}(*)$ & $\mathrm{S}(* *)$ \\
\hline $\begin{array}{l}\mathrm{S}(*) \text { Supported at } 5 \% \text { significance level, } \mathrm{N}=35 \\
\mathrm{~S}(* *) \text { Supported at } 5 \% \text { significance level, } \mathrm{N}=125 \\
\mathrm{NS} \text { : not significant }\end{array}$ & & \\
\hline
\end{tabular}

Table 2: Comparison of results of the Brazilian and US studies (Preston 2004)

Figure 3 illustrates the research model with the hypotheses supported by the analysis 


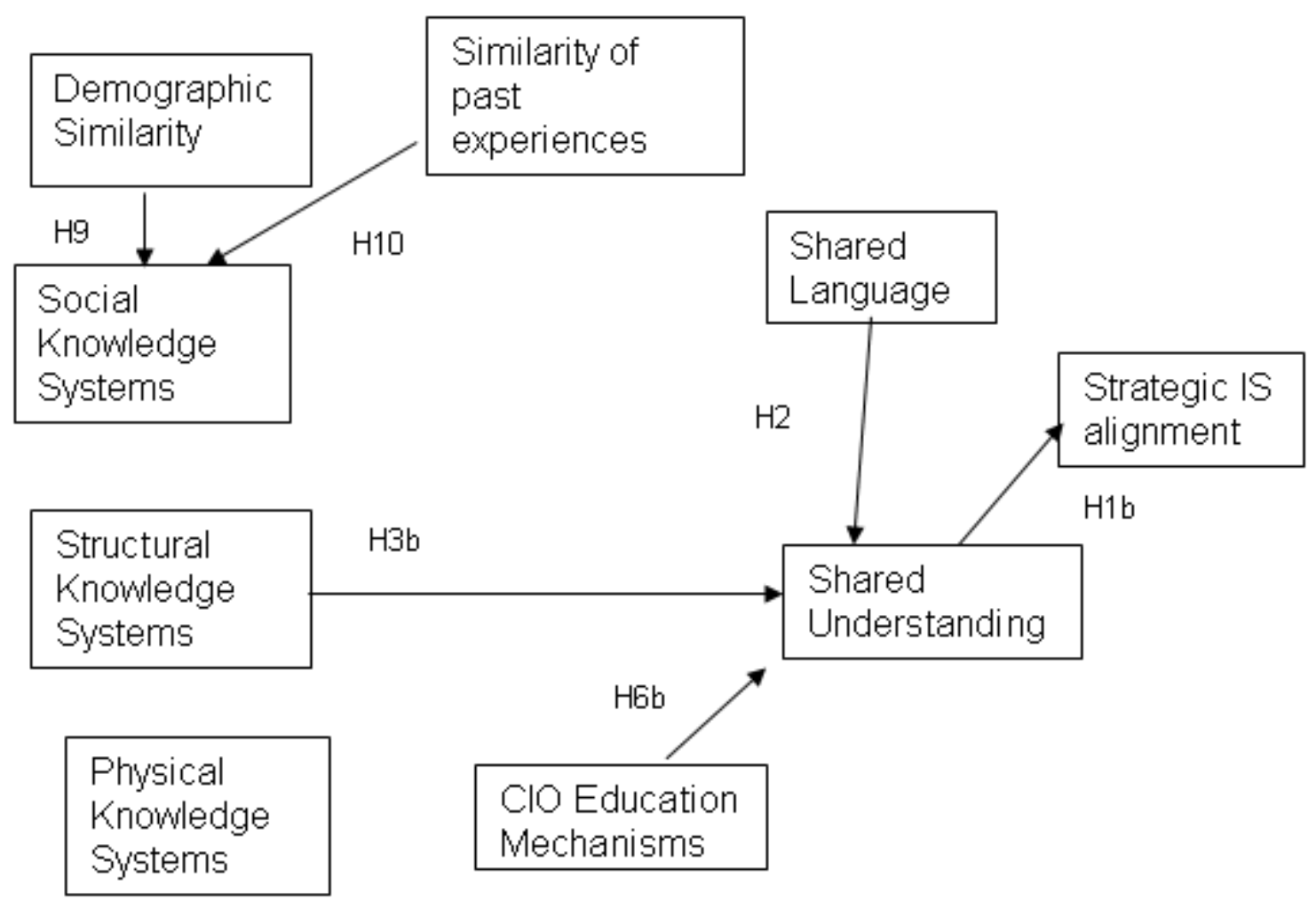

Figure 3: Constructs and significant relationships

Table 3 presents the variance of the dependent variables explained by the model.

\begin{tabular}{|l|l|l|}
\hline Dependent Variable & $\begin{array}{l}\text { Explained Variance } \\
\%\end{array}$ & $\begin{array}{l}\text { Antecedents and significant } \\
\text { paths }\end{array}$ \\
\hline $\begin{array}{l}\text { IS strategic alignment de } \\
\text { SI }\end{array}$ & $35,8 \%$ & Shared Understanding $\left(^{*}\right)$ \\
\hline Shared Understanding & $64,3 \%$ & $\begin{array}{l}\text { Shared Language (*) } \\
\text { Structural Knowledge Systems }\left(^{*}\right) \\
\text { CIO Education Mechanisms }\left(^{*}\right)\end{array}$ \\
\hline $\begin{array}{l}\text { Social Knowledge } \\
\text { Systems }\end{array}$ & $22,1 \%$ & $\begin{array}{l}\text { Demographic Similarity }\left(^{*}\right) \\
\text { Similarity of Past Experiences }\left(^{*}\right)\end{array}$ \\
\hline \begin{tabular}{l}
$(*)$ significant at 5\% level \\
\hline
\end{tabular}
\end{tabular}

Table 3: Dependent Variables' variance explained by the model

\subsubsection{Comparison between the Brazilian and the US (Preston 2004) study results}

Table 2 demonstrates the consistency of the results of both studies. The absence of a significant influence of the social dimension (and even the demographic and past experiences in the Brazilian study) on the development of SMM and IS alignment can be interpreted as the result of a high degree of formality of the CIO function and its relation to the TMT.

Organizational proximity and similarity of past experiences, identified in the Preston 2004 study (Preston 2004) as influencing the development of a shared language between the CIO and the TMT, were not confirmed in our study, a result that can also be interpreted as a sign of the weakening of the strategic role of IS and the CIO. These 
results run against the general belief of the importance of informal relations in the Brazilian national and managerial culture and deserve further research.

\section{CONCLUSIONS}

The first result of the study was a new statistical validation of the constructs proposed by Preston 2004 using the Brazilian sample. The relationships among the constructs that resulted from the analysis are almost identical with the Preston 2004 findings, confirming the robustness of the model.

Strategic IS alignment is, according to our study, influenced by shared understanding, with the latter being influenced by the structural knowledge system and the CIO education mechanisms. In addition, shared understanding is also influenced by the shared language construct.

These findings show that mainly formal aspects determine the CIO/TMT relationship. The social dimensions of the relationship that have been evidenced in other authors' previous research did not show up as significant in our study. In this respect our results differs from the Preston 2004 study which had found also a significant influence of similarity of past experiences and physical knowledge system (organizational proximity) on the shared language construct, and therefore indirectly on the strategic IS alignment.

The answers to the proposed research questions

1. What is the relationship between the SMM and the strategic IS alignment?

The study validated an influence path: structural knowledge system on shared language on the shared understanding between the CIO and the TMT on the strategic IS alignment, with an additional influence of CIO education mechanisms on shared understanding. This path explained $35.8 \%$ of the variance of the strategic IS alignment construct.

Demographic characteristics and shared past experiences were also shown to influence the social knowledge system, but without significant influence on the shared mental model constructs and strategic IS alignment.

2. What are the antecedents to a SMM of the CIO and the TMT?

This study analyzed the influence of two primary antecedents on shared mental models: mechanisms of knowledge exchange and relational similarity. The results support only the influence of structural knowledge systems and CIO education mechanisms as antecedents to Shared Mental Models. These constructs explain a significant $64.3 \%$ of the variance of the shared understanding construct.

As for relational similarity, the constructs were shown to influence only the social knowledge system and explaining only a small percentage of its variation $(22.1 \%)$.

3. Is there a difference between Brazilian and US companies in this respect? 
Our study provided additional support to the Preston 2004 model, by validating again the questionnaire and constructs and high consistency with the results of that research, providing additional evidence to the robustness of the model.

Further research would be required for the analysis of the model in other segments, like public administration, smaller companies, also taking into account the continuously changing of the IT organization and its management.

\section{REFERENCES}

Alavi, M; Leidner, D. (2001) Review: Knowledge management and knowledge management systems: Conceptual foundations and research issues. MIS Quarterly v.25(1):107-133

Allinson, C et al. (2001) The effects of cognitive style on leader-member exchange: A study of manager-subordinate dyads. Journal of Occupational \& Organizational Psychology v.74 (2):201-221.

Armstrong, C. (1995) Creating business value through information technology: The effects of the chief information office and top management team characteristics. College of Business. Tallahassee, Florida, Florida State University.

Armstrong, C. Sambamurthy, V. (1999) Information Technology assimilation in firms: The influence of senior leadership and IT infrastructures. Information Systems Research v.10(4):304-328.

Boynton, Andrew et al. (1992) Whose responsibility is IT management. Sloan Management Review v.33(4):32-39.

Byrne, D. (1971) The attraction paradigm. New York, Academic Press.

Chan, Y. (2002) Why Haven't We Mastered Alignment? The Importance of the Informal Organization Structure. MIS Quarterly Executive v.1(2):97-112.

Daft, R (1987) et al. Message equivocality, media selection and manager performance. MIS Quarterly v.11(3):355-366.

Denzau, A; North, D. (1994) Shared mental models: Ideologies and institutions. Kyklos v.47(1):3-32.

Earl, M; Feeny, D. (1994) Is your CIO adding value? Sloan Management Review v.35(3):11-21.

Enns, H et al. (2003) CIO lateral influence behaviors: Gaining peer's commitment to strategic information systems. MIS Quarterly v.27(1):155-176.

Feeny, D et al. (1992) Understanding the CEO/CIO relationship. MIS Quarterly v.16(4):435-449.

Finkelstein, S; Hambrick, D. (1996) Strategic Leadership: Top Executives and Their Effects on Organizations. Minneapolis, MN, West Publishing Company.

Finneran, M. (2003) The end of hubris: IT doesn't matter. Business Communications Review v.33(7):2-3.

Grover, V et al. (1993) The chief information officer: A study of managerial roles. Journal of Management Information Systems v.10(2):107-131. 
The Influence of Shared Mental Models Between the CIO and the Top Management Team on the Strategic Alignment of Information Systems: A Comparison Between Brazilian and US Companies

Hambrick, D. (1994) Top management groups: A conceptual integration and reconsideration of the team label. Research in Organizational Behavior v.16:171-215.

Hambrick, D; Mason, P. (1984) Upper echelons: The organization as a reflection of its top managers. Academy of Management Review v.9(1):193-206.

Henderson, J; Venkatraman, N. (1999) Strategic alignment: leveraging information technology for transforming organizations. IBM Systems Journal v.38(2/3):472-485.

Hodgkinson, G; Johnson, G. (1994) Exploring the mental models of competitive strategists: The case for a processual approach. Journal of Management Studies v.31(4):525-552.

Karimi, J; Gupta, Y. (1996) The congruence between a firm's competitive strategy and information technology leader's rank and role. Journal of Management Information Systems 13(1):63-89.

Kim, D. (1993) The link between individual and organizational learning. Sloan Management Review v.35(1):37-51.

Lederer, A; Burky, L. (1988) Understanding top management's objectives: A management information systems concern. Journal of Information Systems v.3(1):5067.

Lederer, Albert; Mendelow, Aubrey.(1987) Information resource planning: Overcoming difficulties in identifying top management's objectives. MIS Quarterly v.11(3):388-400,

Leonard, J; Seddon, P. (2012) A Meta-model of Alignment, Communications of the Association for Information Systems: v 31, Article 11.

Madhavan, R; Grover, R. (1998) From embedded knowledge to embodied knowledge: New product development as knowledge management. Journal of Marketing v.62(4):113.

Mohammed, S et al. (2000) The measurement of team mental models: We have no shared schema. Organizational Research Methods v.3(2):123-166

Monge, $\mathrm{P}$ et al. (1985) The dynamics of organizational proximity. Management Science v.31(9):1129-1142.

Nahapiet, J; Ghoshal, S. (1998) Social capital, intellectual capital, and the organizational advantage. Academy of Management Review v.23(2):242-266

Nelson, K; Cooprider, J. (1996) The contribution of shared knowledge to is group performance. MIS Quarterly v.20(4):409-433.

Orpen, C. (1984) Attitude similarity, attraction, and decision-making in the employment interview. Journal of Psychology v.117(1):111-121.

Peterson, E et al. (2000) Collective efficacy and aspects of shared mental models as predictors of performance over time in work groups. Group Processes \& Intergroup Relations v.3(3):296-317.

Preston, D. (2004) Shared Mental Models between the Chief Information Officer and Top Management Team: Towards Information Systems Strategic Alignment, Unpublished PhD Thesis, The University of Georgia, Athens. 
Preston, D; Karahana, E. (2009)How to Develop a Shared Vision: The Key to IS Strategic Alignment. MIS Quarterly Executive 8(1)

Rasker, P.; Post, W. (2000) Effects of two types of intra-team feedback on developing a shared mental model in command and control teams. Ergonomics v.43(8):1167-1190.

Reich, B; Benbasat, I. (1996) Measuring the linkage between business and information technology objectives. MIS Quarterly v.20(1):55-62.

Reich, B; Benbasat, I. (2000) Factors that influence the social dimensions of alignment between business and information technology objectives. MIS Quarterly v.24(1):81-114.

Richards, D. (2001) Coordination and shared mental models. American Journal of Political Science v.45(2):259-267.

Rockart, J et al. (1996) Eight imperatives for the new IT organization. Sloan Management Review v.38(1):43-56.

Sabherwal, R; Chan, Y. (2001) Alignment between business and IS strategies: A study of prospectors, analyzers, and defenders. Information Systems Research v.12(1):11-34.

Sabherwal, R et al. (2001) The Dynamics of Alignment: Insights from a Punctuated Equilibrium Model. Organization Science v.12(1):179-197.

Schrage, M. (1996) Organizational charts really do matter. Computerworld v.30:3334.

Smaltz, D. (1999) Antecedents of CIO effectiveness: A role-based perspective. College of Business. Tallahassee, Florida, Florida State University.

Stephens, C et al. (1992) Executive or functional manager? The nature of the CIO's job. MIS Quarterly v.16(4):449-468.

Swaab, R et al. (2002) Multiparty negotiation support: The role of visualization's influence on the development of shared mental models. Journal of Management Information Systems v.19(1):129-150.

Tallon, P; Pinsonneault, A, (2011) Competing Perspectives on the Link between Strategic Information Technology and Organizational Agility; Insight from a Mediation Model, MIS Quarterly, v35(2): 463-486

Van den Bosch, F; Volberda, H. (1999) Coevolution of firm absorptive capacity and knowledge environment: Organizational forms and combinative capabilities. Organization Science v.10(5):551-569.

Van der Vegt, G. (2002) Effects of attitude dissimilarity and time on social integration: A longitudinal panel study. Journal of Occupational \& Organizational Psychology v.75(4):439-453.

Wagner, W. G et al. (1984) Organizational demography and turnover in top management groups. Administrative Science Quarterly v.29:74-92.

Watson, R. (1990) Influences on the IS manager's perceptions of key issues:Information scanning and the relationship with the CEO. MIS Quarterly v.14(2):217-232

Weill, P. (1990) Strategic investment in information technology: An empirical study. Information Age v.12(3):141-148.

Young, M; Buchholtz, A. (2002) Firm performance and CEO pay: Relational demography as a moderator. Journal of Managerial Issues v.14(3):296-314. 